\title{
Xerosis cutis and associated co-factors in women with prurigo nodularis*
}

\author{
Sevgi Akarsu' ${ }^{1}$, Ozlem Ozbagcivan ${ }^{1}$, Turna Ilknur ${ }^{1}$, Fatma Semiz ${ }^{1}$, Burcu Bahar Inci ${ }^{1}$, Emel Fetil ${ }^{1}$
}

DOI: http:/ / dx.doi.org/10.1590/abd1806-4841.20187127

\begin{abstract}
BACKGROUND: Current data regarding the associated factors of prurigo nodularis are still uncertain, except for atopic predisposition.

OBJECTIVES: The purposes of this study were to (1) determine the frequencies of xerosis and other accompanying diseases of female patients with prurigo nodularis; (2) compare the demographic, clinical and accompanying disease characteristics by grouping these patients according to whether they have associated xerosis (who were subsequently subgrouped as atopic or non-atopic) or not.

METHODS: In this retrospective descriptive study, 80 females with PN were categorized according to the accompanying diseases (dermatological, systemic, neurological, psychogenic, mixed, or undetermined origin).

RESULTS: A total of 45 associated co-factors including dermatological in 63 (78.8\%), systemic in 57 (71.3\%), psychological in 33 $(41.3 \%)$ and neurological co-factors in $14(17.5 \%)$ of all patients with prurigo nodularis were detected. Xerosis was observed in $48(60 \%)$ patients (non-atopic co-factors in $66.7 \%$ of them). The ratio of patients with mixed co-factors, dermatological+systemic co-factors and dermatological+systemic+psychological co-factors were found to be significantly higher in patients with xerosis compared to those without xerosis.

STUDY LIMITATIONS: Our study has certain limitations such as the absence of an age-matched control group, absence of follow-up data and the fact that the diagnosis of xerosis has not been based on objective methods.

CONCLUSIONS: Xerosis has been identified in more than half of the patients with PN and it has been determined that in most patients xerosis is associated especially with diabetes mellitus and other conditions related to prurigo nodularis.

Keywords: Dermatitis, atopic; Female; Prurigo
\end{abstract}

\section{INTRODUCTION}

It is well known that impulse control disorders affecting the skin (such as skin picking and neurotic excoriations) primarily affect middle-aged women. ${ }^{1,2}$ One of these troublesome diseases is chronic pruritus $(\mathrm{CP}$, itching lasting for $\geq 6$ weeks) which has been extensively investigated in recent years and may rarely lead to the development of prurigo nodularis (PN) following intense and long-term itch-scratch cycles. ${ }^{3,4}$ It has been demonstrated in a study with large case series that multiple lesions related to itching and PN are more frequently observed in women with $\mathrm{CP}$ when compared to men. Moreover, multifactorial, neuropathic and psychosomatic diseases in relation with CP are at higher rates in women. ${ }^{3}$ Also in another study, it has been identified that the rates of decrease in quality of

\footnotetext{
Received 22 March 2017.

Accepted 20 August 2017.

* Work conducted at the Department of Dermatology, Faculty of Medicine, Dokuz Eylul University, Izmir, Turkey.

Financial support: None.

Conflict of interest: None.

1 Department of Dermatology, Faculty of Medicine, Dokuz Eylul University, Izmir, Turkey.
}

E-mail: ozlem.ozbagcivan@deu.edu.tr 
life with anxiety and itching intensity are higher in women when compared to men. ${ }^{4}$

$\mathrm{PN}$ is characterized by hyperkeratotic excoriated papulonodular lesions that show symmetrical distribution on the extensor surfaces of the body and/or extremities, the numbers of which range from several to hundreds. Although it can be observed in all ages and genders, it frequently affects middle-aged women with an accompanying comorbidity. ${ }^{5-7}$ It is a rare disease and is one of the most difficult conditions in terms of determining its etiology and treatment among chronic skin diseases. ${ }^{5}$ Although it is observed that the underlying causes have formed a broad spectrum from atopic diathesis to malignant lymphomas, the data in the literature regarding the predisposing factors contributing to the development of PN are still uncertain, except for an atopic predisposition. . $^{5-12}$

Xerosis cutis (dry skin) is also an important factor that can contribute to the development of PN with $\mathrm{CP}$ and progressive itchscratch cycle. ${ }^{5-7,13}$ Although xerosis, ever-increasing with age, often appears as being associated with an atopic condition (atopic xerosis), it is also a frequent symptom in some skin diseases (the most frequent in atopic dermatitis) and in chronic systemic diseases (such as endocrine disorders, renal failure, liver diseases, malignancies and infections). ${ }^{13-15}$ Upon reviewing the literature, no study examining the presence of xerosis within the conditions accompanying PN has been found.

In this study, the objective was first to determine the demographic and clinical characteristics, and the frequencies of xerosis, atopic diathesis and other accompanying diseases of female patients with PN. We also intended to compare demographic, clinical and accompanying disease characteristics by grouping these patients according to whether they have accompanying xerosis or not and the patients with xerosis according to the presence of the current atopic or non-atopic factors.

\section{METHODS}

This is a retrospective descriptive study, including 80 women with clinicopathologically diagnosed PN who were consecutively admitted to the outpatient clinic of the Department of Dermatology of Dokuz Eylul University Faculty of Medicine in Izmir, Turkey, between January 2010 and December 2016. The study protocol was approved by the Local Ethical Committee (the number of Research Ethics Committee: 2015/16-18) which follows the guidelines set by the Declaration of Helsinki. Patients' files were examined, and their demographic and clinical characteristics such as ages, the age of PN onset and age distributions (early adulthood; $19-45$ years, middle adulthood; 46-64 years, and later adulthood; $\geq 65$ years), duration of $\mathrm{PN}$, distribution and site of lesions were recorded. The medical histories, physical examinations and laboratory investigations as well as the results of consultations and additional examinations required from the relevant departments when necessary in the clinical evaluation periods of the patients were taken into account in determining accompanying xerosis, atopic diathesis (allergic rhinitis/rhinoconjunctivitis, bronchial asthma and/or atopic dermatitis) and other PN-related diseases. Patients with missing data were not included in the study. Xerosis was clinically determined by the presence of features such as roughening on the skin, flaking and/or fissures.
Only the diseases that were known to have the potential to lead to itching and were recently correlated with PN development were considered as PN-related diseases. ${ }^{13,16}$ However, a clear correlation between all etiological factors and PN onset could not be shown due to the coexistence of the majority of associated underlying conditions in patients with PN. Using the classification of the International Forum for the Study of Itch ${ }^{16}$, our patients with PN were categorized according to the accompanying disease (dermatological, systemic, neurological, psychogenic, mixed, or undetermined origin).

Patients with PN without xerosis (group A) and with xerosis (group B) were firstly compared for the statistical analysis, then, among the patients with $\mathrm{PN}$ and xerosis, the subgroups atopic xerosis (subgroup B1) and xerosis related to other reasons (non-atopic) (subgroup B2) were compared among themselves. The data were analyzed using SPSS software (SPSS 15, SPSS Inc., Chicago, Illinois, USA). The Shapiro-Wilk test was used to examine the normality of the distribution of the data. Numerical variables were described by mean and standard deviation if they were normally distributed, and by median and interquartile range if they were not normally distributed. Two samples Student's t-test was used to compare mean values of normally distributed quantitative variables as the two samples were obtained independently, and Mann Whitney U-test was used if the variables were not normally distributed. Qualitative variables were analyzed with chi-squared test and Fisher's exact test. $\mathrm{P}<.05$ was considered significant in all analyses. Furthermore, the Hosmer-Lemeshow goodness-of-fit test for logistic regression was used to evaluate the association of each category of accompanying co-factors in the presence of the others. A Type 1 error rate of less than $5 \%$ was considered significant in this analysis.

\section{RESULTS}

Xerosis was observed in 48 (60\%) of a total of 80 female patients with PN who were included in the study, while the presence of at least one atopic diathesis was identified (atopic xerosis) in 16 (33.3\%) of them, atopy history was not determined in $32(66.7 \%)$ of the remaining (non-atopic xerosis).

\section{Demographic and clinical characteristics}

Both the age and the PN onset age averages of the patient group with xerosis were found to be higher compared to those without xerosis $(p<0.001)$. While the ratio of the patients whose PN lesions had started in the early adulthood period was higher in the PN group without xerosis, the patients whose PN lesions had started in the later adulthood period were found to be at a higher rate in the group with xerosis (Table 1).

In patients with xerosis, the age and the $\mathrm{PN}$ onset age averages of the atopic xerosis group were found to be lower compared to the patients with non-atopic xerosis $(p<0.001)$. While the ratio of patients whose PN lesions had started in the early adulthood period was more in the atopic xerosis group, patients whose PN lesions had started in the middle adulthood and later adulthood period were found to be at a higher rate in the non-atopic xerosis group. The mean PN disease duration was also found to be longer in the atopic xerosis group (Table 1). 


\begin{tabular}{|c|c|c|c|c|c|c|c|}
\hline \multirow[t]{2}{*}{ Variables } & \multirow{2}{*}{$\begin{array}{c}\text { All } \\
\text { patients }\end{array}$} & \multirow{2}{*}{$\begin{array}{l}\text { Xerosis (-) } \\
\text { (Group A) }\end{array}$} & \multirow{2}{*}{$\begin{array}{l}\text { Xerosis }(+) \\
\text { (Group B) }\end{array}$} & \multicolumn{2}{|c|}{ Xerosis (+) (Group B) } & \multicolumn{2}{|c|}{$P$ values } \\
\hline & & & & $\begin{array}{l}\text { Atopic xerosis } \\
\text { (Subgroup B1) }\end{array}$ & $\begin{array}{c}\text { Non-atopic } \\
\text { xerosis } \\
\text { (Subgroup B2) }\end{array}$ & A vs B & $\begin{array}{c}\text { B1 vs } \\
\text { B2 }\end{array}$ \\
\hline Number of patients, $\mathrm{n}(\%)$ & $80(100)$ & $32(40)$ & $48(60)$ & $16(20)$ & $32(40)$ & - & - \\
\hline \multicolumn{8}{|l|}{ Age of patients } \\
\hline Mean $\pm S D$ (min-max), years & $\begin{array}{c}53.1 \pm 17.2 \\
(19-90)\end{array}$ & $\begin{array}{c}45.0 \pm 12.7 \\
(22-67)\end{array}$ & $\begin{array}{c}58.6 \pm 17.7 \\
(19-90)\end{array}$ & $\begin{array}{c}41.3 \pm 13.5 \\
(19-69)\end{array}$ & $\begin{array}{c}67.2 \pm 12.6 \\
(33-90)\end{array}$ & $<0.001$ & $<0.001$ \\
\hline \multicolumn{8}{|l|}{ PN onset age } \\
\hline Mean \pm SD (min-max), years & $\begin{array}{c}47.9 \pm 18.1 \\
(14-88)\end{array}$ & $\begin{array}{c}38.5 \pm 12.1 \\
(16-59)\end{array}$ & $\begin{array}{c}54.1 \pm 18.9 \\
(14-88)\end{array}$ & $\begin{array}{c}34.6 \pm 13.5 \\
(14-67)\end{array}$ & $\begin{array}{c}63.8 \pm 12.7 \\
(33-88)\end{array}$ & $<0.001$ & $<0.001$ \\
\hline \multicolumn{8}{|l|}{ Distribution, n (\%) } \\
\hline Early adulthood & $41(51.3)$ & $23(71.9)$ & $18(37.5)$ & $14(87.5)$ & $4(12.5)$ & & \\
\hline Middle adulthood & $22(27.5)$ & $9(28.1)$ & $13(27.1)$ & $1(6.3)$ & $12(37.5)$ & & \\
\hline Later adulthood & $17(21.3)$ & 0 & $17(35.4)$ & $1(6.3)$ & $16(50)$ & & \\
\hline \multicolumn{8}{|l|}{ Duration of PN * } \\
\hline $\begin{array}{l}\text { Median (interquartile range), } \\
\text { months }\end{array}$ & $\begin{array}{c}48.0 \\
(24-84)\end{array}$ & $\begin{array}{c}60 \\
(24-132)\end{array}$ & $42(24-69)$ & $60(36-93)$ & $30(12-60)$ & 0.103 & 0.014 \\
\hline \multicolumn{8}{|l|}{ Distribution of PN, n (\%) } \\
\hline Localized & $12(15)$ & $7(21.9)$ & $5(10.4)$ & $3(18.8)$ & $2(6.3)$ & 0.206 & 0.316 \\
\hline Generalized & $68(85)$ & $25(78.1)$ & $43(89.6)$ & $13(81.3)$ & $30(93.8)$ & & \\
\hline \multicolumn{8}{|l|}{ Location of PN, n (\%) } \\
\hline Lower limbs & $69(86.3)$ & $28(87.5)$ & $41(85.4)$ & $15(93.8)$ & $26(81.3)$ & 1.00 & 0.398 \\
\hline Trunk & $47(58.8)$ & $20(62.5)$ & $27(56.3)$ & $6(37.5)$ & $21(65.6)$ & 0.578 & 0.064 \\
\hline Upper limbs & $18(22.5)$ & $7(21.9)$ & $11(22.9)$ & $3(18.8)$ & $8(25)$ & 0.913 & 0.729 \\
\hline Head and neck & $8(10)$ & $5(15.6)$ & $3(6.3)$ & $1(6.3)$ & $2(6.3)$ & 0.256 & 1.00 \\
\hline \multicolumn{8}{|l|}{ Number of affected areas * } \\
\hline Median (interquartile range) & $2(1-2)$ & $2(1-2)$ & $2(1-2)$ & $1(1-2)$ & $2(1.25-2)$ & 0.436 & 0.135 \\
\hline
\end{tabular}

PN, prurigo nodularis; Boldfaced $\mathrm{P}$ values indicate statistical significance $(\mathrm{P}<0.05)$.

*; Numerical variables without normal distribution were analyzed with Mann-Whitney U test

\section{Number and category of associated factors:}

No associated factor was found in $2(2.5 \%)$ of the patients with PN (the category of undetermined factor). Atopic diathesis was determined in $7(8.8 \%)$ of $12(15 \%)$ patients with a single factor associated with PN, different diseases including nummular dermatitis, urticaria, iron deficiency anemia, hepatitis B virus infection and depression were identified in the remaining $5(6.7 \%)$ patients. More than one associated co-factor was determined in the majority of patients with PN $(82.5 \%)$. The mean number of the co-factors associated with PN $(p<0.001)$ and thus the ratio of patients in which mixed co-factors $(p=0.008)$ was determined were found to be significantly higher in the patient group with xerosis compared to patients without xerosis. The combinations of dermatological+systemic and dermatological+systemic+psychological co-factors that were most frequently determined among mixed co-factors were found to be significantly more common in the patient group with xerosis compared to those without xerosis. In patients with xerosis, the number of associated co-factors $(p=0.001)$ and the frequency of the associated mixed co-factor combinations (although there was not statistically significant) were found to be more frequent in the non-atopic xerosis group compared to patients with atopic xerosis (Table 2).

Analysis of associated co-factors in patients with PN

A total of 45 associated co-factors including dermatological in $63(78.8 \%)$, systemic in $57(71.3 \%)$, physiological in $33(41.3 \%)$ and neurological co-factors in $14(17.5 \%)$ of all patients with PN were detected. At least one atopic diathesis was determined in a total of $27(33.8 \%)$ patients including allergic rhinoconjunctivitis in 12 $(15 \%)$, allergic asthma in $8(10 \%)$ and atopic dermatitis in $9(11.3 \%)$ of the patients. The frequency of systemic cofactors was found to 


\begin{tabular}{|c|c|c|c|c|c|c|c|}
\hline \multirow{2}{*}{ Associated diseases, n (\%) } & \multirow{2}{*}{$\begin{array}{c}\text { All } \\
\text { patients } \\
(n=80)\end{array}$} & \multirow{2}{*}{$\begin{array}{c}\text { Xerosis (-) } \\
\text { (Group A) } \\
(n=32)\end{array}$} & \multirow{2}{*}{$\begin{array}{c}\text { Xerosis (+) } \\
(\text { Group B) } \\
(\mathrm{n}=48)\end{array}$} & \multicolumn{2}{|c|}{ Xerosis (+) (Group B) } & \multicolumn{2}{|c|}{$P$ values } \\
\hline & & & & $\begin{array}{l}\text { Atopic xerosis } \\
\text { (Subgroup } \\
\text { B1) }(n=16)\end{array}$ & $\begin{array}{c}\text { Non-atopic } \\
\text { xerosis } \\
\text { (Subgroup B2) } \\
(n=32)\end{array}$ & A vs B & B1 vs B2 \\
\hline \multicolumn{8}{|l|}{ Number of associated co-factors $\ddagger$} \\
\hline Median (interquartile range) & $3(2-4)$ & $2(1-3)$ & $4(2-5)$ & $3(2-3.8)$ & $4(3-5)$ & $<0.001$ & 0.001 \\
\hline \multicolumn{8}{|l|}{ Category of associated factors } \\
\hline Undetermined factor & $2(2.5)$ & $2(6.3)$ & $0(0)$ & $0(0)$ & $0(0)$ & 0.157 & - \\
\hline Single factor & $12(15)$ & $8(25)$ & $4(8.3)$ & $4(25)$ & $0(0)$ & 0.056 & 0.101 \\
\hline Mixed co-factors & $66(82.5)$ & $22(68.8)$ & $44(91.7)$ & $13(81.3)$ & $31(96.9)$ & 0.008 & 0.101 \\
\hline Dermatological + systemic* & $20(25)$ & $3(9.4)$ & $17(35.4)$ & $5(31.3)$ & $12(37.5)$ & & \\
\hline $\begin{array}{l}\text { Dermatological + systemic }+ \\
\text { psychological }^{*}\end{array}$ & $16(20)$ & $3(9.4)$ & $13(27.1)$ & $3(18.8)$ & $10(31.3)$ & & \\
\hline Dermatological + psychological ${ }^{*}$ & $6(7.5)$ & $4(12.5)$ & $2(4.2)$ & $2(12.5)$ & $0(0)$ & & \\
\hline $\begin{array}{l}\text { Dermatological + systemic }+ \\
\text { psychological + neurological }\end{array}$ & $6(7.5)$ & $1(3.1)$ & $5(1)$ & $1(6.3)$ & $4(12.5)$ & & \\
\hline $\begin{array}{l}\text { Dermatological }+ \text { systemic }+ \\
\text { neurological }\end{array}$ & $5(6.3)$ & $0(0)$ & $5(1)$ & $0(0)$ & $5(15.6)$ & & \\
\hline Systemic + psychological & $4(5)$ & $4(12.5)$ & $0(0)$ & $0(0)$ & $0(0)$ & & \\
\hline Multiple systemic & $2(2.5)$ & $2(6.3)$ & $0(0)$ & $0(0)$ & $0(0)$ & & \\
\hline Multiple dermatological & $2(2.5)$ & $0(0)$ & $2(4.2)$ & $2(12.5)$ & $0(0)$ & & \\
\hline Systemic + neurological & $1(1.3)$ & $1(3.1)$ & $0(0)$ & $0(0)$ & $0(0)$ & & \\
\hline Atopic diathesis + other co-factors $* *$ & $4(5)$ & $4(12.5)$ & $0(0)$ & $0(0)$ & $0(0)$ & & \\
\hline
\end{tabular}

Boldfaced $\mathrm{P}$ values indicate statistical significance $(\mathrm{P}<0.05)$.

*In these groups with mixed co-factors, atopic diathesis was also present in one patient.

**Dermatological/systemic/psychological/neurological factors were present in each one patient in addition to atopic diathesis

‡; Numerical variables without normal distribution were analyzed with Mann-Whitney U test

be significantly higher in the patient group with xerosis compared to those without xerosis $(p=0.003)$, and in the patient group with non-atopic xerosis within the group with xerosis compared to those with atopic xerosis $(p=0.001)$. While the systemic factors most frequently associated with PN were iron deficiency anemia (27.5\%) and diabetes mellitus (26.3\%), association with diabetes mellitus was most frequently observed in the xerosis group (35.4\%) and in the non-atopic ones $(46.9 \%)$ (Table 3$)$. When all co-factor groups (dermatological, systemic, psychological, neurological) were evaluated together in the presence of others by using logistic regression analysis, only the presence of systemic co-factors category appears to statistically significantly increase PN development in the patient groups with xerosis (4.04 times) and non-atopic xerosis (25.08 times higher risk as compared to non-xerosis group, 24.95 times higher risk as compared to atopic-xerosis group) (Table 4).

\section{DISCUSSION}

In the Global Burden of Disease study, pruritus has been categorized among the top 50 most prevalent diseases (not only skin but all diseases) worldwide and thus it carries a high burden, especially among the elderly population. ${ }^{17}$ Xerosis, which is detected in $30-85 \%$ of the elderly people, is the most common cause of itch in this age group. ${ }^{14,15}$ Xerosis also increases in direct proportion to age due to changes in the barrier function of the stratum corneum that occur during the normal aging process (such as cellular and intercellular lipid matrix changes, $\mathrm{pH}$ variations, alterations in stratum corneum proteases, decreased activity of sebaceous and sweat glands, decreased oestrogen levels). In a study conducted by Paul et al., the most significant risk factors associated with the development of xerosis in elderly people were advanced age, female gender, the presence of current atopic dermatitis or the history of previous atopic dermatitis. ${ }^{18}$ In another study examining the underlying diseases in patients with severe $\mathrm{CP}$, it has been determined that the patient group with multifactorial etiology was over the age of 65 years and female, the most frequently observed skin changes were PN (76.9\%) and xerosis $(42.2 \%)$, and metabolic-endocrine and hematological disorders also accompanied more frequently. ${ }^{7}$ As can be expected, the treatment of such patients with systemic antipruritic drugs is difficult because of the possibility of contraindications relating to concurrent systemic diseases and the increased frequency of side effects or drug interactions in old age. Therefore, the most important and first step in CP and PN treatment is to determine the underlying cause. ${ }^{5,7}$

The data associated with the total incidence of underlying causal factors in patients with PN are quite insufficient. Most of them have been obtained from case reports and only a few number 
TABLE 3: Analysis of co-factors in women with prurigo nodularis (total number of co-factors $=45$ )

\begin{tabular}{|c|c|c|c|c|c|c|c|}
\hline \multirow[t]{2}{*}{ Co-factors, n (\%) } & \multirow{2}{*}{$\begin{array}{c}\text { All } \\
\text { patients } \\
(n=80)\end{array}$} & \multirow{2}{*}{$\begin{array}{l}\text { Xerosis (-) } \\
\text { (Group } \\
\text { A) }(n=32)\end{array}$} & \multirow{2}{*}{$\begin{array}{c}\text { Xerosis }(+) \\
(\text { Group B) } \\
(n=48)\end{array}$} & \multicolumn{2}{|c|}{ Xerosis (+) (Group B) } & \multicolumn{2}{|c|}{$P$ values } \\
\hline & & & & $\begin{array}{c}\text { Atopic xerosis } \\
\text { (Subgroup B1) } \\
(\mathrm{n}=16)\end{array}$ & $\begin{array}{c}\text { Non-atopic } \\
\text { xerosis } \\
\text { (Subgroup B2) } \\
(\mathrm{n}=32)\end{array}$ & A vs $B$ & B1 vs B2 \\
\hline Dermatological co-factors & $63(78.8)$ & $15(46.9)$ & $48(100)$ & $16(100)$ & $32(100)$ & $<0.001$ & - \\
\hline Xerosis cutis & $48(60)$ & $0(0)$ & $48(100)$ & $16(100)$ & $32(100)$ & & \\
\hline $\begin{array}{l}\text { Atopic diathesis } \\
\text { (including atopic dermatitis) }\end{array}$ & $27(33.8)$ & $11(34.4)$ & $16(33.3)$ & $16(100)$ & $0(0)$ & & \\
\hline Tinea pedis & $10(12.5)$ & $4(12.5)$ & $6(12.5)$ & $1(6.3)$ & $5(15.6)$ & & \\
\hline Xerotic eczema & $4(5)$ & $0(0)$ & $4(8.3)$ & $0(0)$ & $4(12.5)$ & & \\
\hline Urticaria & $4(5)$ & $2(6.3)$ & $2(4.2)$ & $1(6.3)$ & $1(3.1)$ & & \\
\hline Post-scabies dermatitis & $3(3.8)$ & $0(0)$ & $3(6.3)$ & $0(0)$ & $3(9.4)$ & & \\
\hline Psoriasis & $2(2.5)$ & $1(3.1)$ & $1(2.1)$ & $1(6.3)$ & $0(0)$ & & \\
\hline Macular amyloidosis & $2(2.5)$ & $1(3.1)$ & $1(2.1)$ & $1(6.3)$ & $0(0)$ & & \\
\hline Stasis dermatitis & $2(2.5)$ & $1(3.1)$ & $1(2.1)$ & $0(0)$ & $1(3.1)$ & & \\
\hline Nummular dermatitis & $2(2.5)$ & $1(3.1)$ & $1(2.1)$ & $1(6.3)$ & $0(0)$ & & \\
\hline Seborrheic dermatitis & $2(2.5)$ & $1(3.1)$ & $1(2.1)$ & $1(6.3)$ & $0(0)$ & & \\
\hline Pemphigoid & $2(2.5)$ & $1(3.1)$ & $1(2.1)$ & $0(0)$ & $1(3.1)$ & & \\
\hline Allergic contact dermatitis & $1(1.3)$ & $0(0)$ & $1(2.1)$ & $1(6.3)$ & $0(0)$ & & \\
\hline Lichen planus & $1(1.3)$ & $1(3.1)$ & $0(0)$ & $0(0)$ & $0(0)$ & & \\
\hline Systemic co-factors & $57(71.3)$ & $17(53.1)$ & $40(83.3)$ & $9(56.3)$ & $31(96.9)$ & 0.003 & 0.001 \\
\hline İron deficiency anemia & $22(27.5)$ & $9(28.1)$ & $13(27.1)$ & $2(12.5)$ & $11(34.4)$ & & \\
\hline Diabetes mellitus & $21(26.3)$ & $4(12.5)$ & $17(35.4)$ & $2(12.5)$ & $15(46.9)$ & & \\
\hline Hypothyroidism & $15(18.8)$ & $1(3.1)$ & $14(29.2)$ & $2(12.5)$ & $12(37.5)$ & & \\
\hline Chronic infections $^{a}$ & $20(25)$ & $6(18.8)$ & $14(29.2)$ & $2(12.5)$ & $12(37.5)$ & & \\
\hline Malignancy $^{\mathrm{b}}$ & $5(6.3)$ & $1(3.1)$ & $4(8.3)$ & $3(18.8)$ & $1(3.1)$ & & \\
\hline Hyperthyroidism & $2(2.5)$ & $0(0)$ & $2(4.2)$ & $0(0)$ & $2(6.3)$ & & \\
\hline Chronic kidney disease & $3(3.8)$ & $0(0)$ & $3(6.3)$ & $0(0)$ & $3(9.4)$ & & \\
\hline Cholestatic liver disease $^{c}$ & $3(3.8)$ & $1(3.1)$ & $2(4.2)$ & $1(6.3)$ & $1(3.1)$ & & \\
\hline Sarcoidosis & $2(2.5)$ & $1(3.1)$ & $1(2.1)$ & $0(0)$ & $1(3.1)$ & & \\
\hline Sjogren syndrome & $2(2.5)$ & $1(3.1)$ & $1(2.1)$ & $0(0)$ & $1(3.1)$ & & \\
\hline Psychological co-factors & $33(41.3)$ & $13(40.6)$ & $20(41.7)$ & $6(37.5)$ & $14(43.8)$ & 0.926 & 0.679 \\
\hline Depression & $30(37.5)$ & $12(37.5)$ & $18(37.5)$ & $6(37.5)$ & $12(37.5)$ & & \\
\hline Anxiety & $14(17.5)$ & $4(12.5)$ & $10(20.8)$ & $1(6.3)$ & $9(28.1)$ & & \\
\hline Stress & $10(12.5)$ & $4(12.5)$ & $6(12.5)$ & $2(12.5)$ & $4(12.5)$ & & \\
\hline Obsessive compulsive disorder & $3(3.8)$ & $0(0)$ & $3(6.3)$ & $0(0)$ & $3(9.4)$ & & \\
\hline Neurological co-factors & $14(17.5)$ & $3(9.4)$ & $11(22.9)$ & $1(6.3)$ & $10(31.3)$ & 0.118 & 0.073 \\
\hline Peripheral neuropathy & $4(5)$ & $1(3.1)$ & $3(6.3)$ & $0(0)$ & $3(9.4)$ & & \\
\hline Migraine & $4(5)$ & $2(6.3)$ & $2(4.2)$ & $1(6.3)$ & $1(3.1)$ & & \\
\hline Lumbar hernia & $3(3.8)$ & $0(0)$ & $3(6.3)$ & $0(0)$ & $3(9.4)$ & & \\
\hline Cervical hernia & $1(1.3)$ & $0(0)$ & $1(2.1)$ & $0(0)$ & $1(3.1)$ & & \\
\hline Cerebrovascular accident & $1(1.3)$ & $0(0)$ & $1(2.1)$ & $0(0)$ & $1(3.1)$ & & \\
\hline Parkinson disease & $1(1.3)$ & $0(0)$ & $1(2.1)$ & $0(0)$ & $1(3.1)$ & & \\
\hline Alzheimer disease & $1(1.3)$ & $0(0)$ & $1(2.1)$ & $0(0)$ & $1(3.1)$ & & \\
\hline
\end{tabular}

- Chronic infections $s^{\mathrm{a}}$ : Helicobacter pylori-positive gastritis, in 12 (15\%) patients; hepatitis B virus infection, odontogenic infection or chronic tonsillitis in each 3 (3.8\%) patients; hepatic hydatid cyst, in $2(2.5 \%)$ patients; toxocariasis, in $1(1.3 \%)$ patient

- Malignancy : Lymphoma, in $3(3.8 \%)$ patients; lung carcinoma or endometrial carcinoma in $1(1.3 \%)$ patient each

- Cholestatic liver disease ${ }^{c}$ : Liver cysts, primary biliary cirrhosis or sclerosing cholangitis in $1(1.3 \%)$ patient each 


\section{TABLE 4: Logistic regression model to evaluate the association of co-factors}

\begin{tabular}{|c|c|c|c|c|c|c|c|c|}
\hline \multirow[t]{2}{*}{$\begin{array}{l}\text { PN-associated } \\
\text { co-factors }\end{array}$} & \multicolumn{2}{|c|}{$\begin{array}{l}\text { Xerosis Reference: non- } \\
\text { xerosis group }\end{array}$} & \multicolumn{2}{|c|}{$\begin{array}{l}\text { Atopic Xerosis Reference: } \\
\text { non-xerosis group }\end{array}$} & \multicolumn{2}{|c|}{$\begin{array}{l}\text { Non-atopic Xerosis Refer- } \\
\text { ence: non-xerosis group }\end{array}$} & \multicolumn{2}{|c|}{$\begin{array}{c}\text { Non-atopic Xerosis } \\
\text { Reference: atopic xerosis } \\
\text { group }\end{array}$} \\
\hline & RR $(95 \% \mathrm{CI})$ & P values & RR (95\% CI) & P values & RR $(95 \%$ CI) & P values & RR (95\% CI) & $P$ values \\
\hline $\begin{array}{l}\text { Systemic co- } \\
\text { factors }\end{array}$ & $4.04(1.39$ - 11.73) & 0.01 & $\begin{array}{c}1.19 \\
(0.35-4.06)\end{array}$ & 0.79 & $\begin{array}{c}25.08 \\
(2.95-212.97)\end{array}$ & 0.01 & $\begin{array}{c}24.95 \\
(2.27-274.4)\end{array}$ & 0.01 \\
\hline $\begin{array}{l}\text { Dermatological } \\
\text { co-factors }\end{array}$ & $1.08(0.41-2.83)$ & 0.87 & $\begin{array}{c}1.10 \\
(0.33-3.73)\end{array}$ & 0.88 & $\begin{array}{c}1.25 \\
(0.39-4.03)\end{array}$ & 0.71 & $\begin{array}{c}0.53 \\
(0.11-2.45)\end{array}$ & 0.41 \\
\hline $\begin{array}{l}\text { Psychological } \\
\text { co-factors }\end{array}$ & $0.82(0.69-0.82)$ & 0.69 & $\begin{array}{c}0.86 \\
(0.25-3.02)\end{array}$ & 0.82 & $\begin{array}{c}0.80 \\
(.025-2.61)\end{array}$ & 0.72 & $\begin{array}{c}0.80 \\
(0.19-3.47)\end{array}$ & 0.77 \\
\hline $\begin{array}{l}\text { Neurological } \\
\text { co-factors }\end{array}$ & $2.09(0.50-8.69)$ & 0.31 & $\begin{array}{c}0.65 \\
(0.06-7.06)\end{array}$ & 0.72 & $\begin{array}{c}3.25 \\
(0.68-15.55)\end{array}$ & 0.14 & $\begin{array}{c}3.61 \\
(0.39-33.47)\end{array}$ & 0.26 \\
\hline $\begin{array}{l}\text { Logistic } \\
\text { regression } \\
\text { model, Hosmer- } \\
\text { Lemeshow test }\end{array}$ & \multicolumn{2}{|l|}{$\mathrm{P}=0.82$} & \multicolumn{2}{|c|}{$\mathrm{P}=0.57$} & \multicolumn{2}{|c|}{$\mathrm{P}=0.92$} & \multicolumn{2}{|c|}{$\mathrm{P}=0.72$} \\
\hline
\end{tabular}

PN, prurigo nodularis; RR, relative risk; $\% 95 \mathrm{CI}, 95 \%$ confidence interval

of clinical studies (as a small retrospective case series ranging from 37 to 108 patients) are available. ${ }^{8-12}$ Iking et al. ${ }^{12}$ have carried out the cohort study with the largest case series $(n=108)$ to date, and our study is the second in the rank in terms of the larger numbers of patients and includes only female cases in whom PN is significantly more frequently observed in the literature.

In clinical studies investigating the etiology of $\mathrm{PN}$, an underlying disease has been found in a total of $87-100 \%$ of the patients and associated with multi-factorial origin in more than half of them (51-59.3\%). An atopic diathesis has been determined in a significant proportion of the patients (22-46.9\%), and it has been found that these patients are more susceptible to triggers that cause itch. ${ }^{11,12}$ Various dermatological (53.7-82\%), systemic (38-70.9\%), psychological (10.2-30\%) and neurological (9.3\%) diseases that are thought to be associated with PN have been observed at different ratios. ${ }^{8-12}$ In our study, the majority of the underlying conditions have consisted of dermatological and systemic co-factors, and they have been followed by psychological and neurological co-factors, in line with literature. The coexistence of dermatological and systemic co-factors has been the most common combination detected in patients with multifactorial etiology in previous studies, as well as in our patients. As the second combination, the coexistence of dermatological and psychological co-factors and the coexistence of multiple systemic co-factors have been reported by Tan et al. and Iking et al., respectively. The authors have suggested that the coexistence of these factors can be coincidental and can play a role as the co-factors contributing to the worsening or chronicity of the symptoms. ${ }^{11,12}$ Diabetes mellitus-associated xerosis was also the most common systemic co-factor detected in patients with multifactorial etiology by Tan et al. ${ }^{11}$, similar to our results. The rates of the incidence of iron deficiency anemia in $\mathrm{PN}$ have been reported to be between 5.2$14.8 \%$ in the literature. ${ }^{10-12}$ However, in another study reported by Polat et al. from our country, the most commonly associated cause in patients with generalized pruritus was iron deficiency anemia, as in our patients. ${ }^{19}$ It has been mentioned that atopic diathesis has been most frequently observed among the dermatological co-factors determined in previous studies, and it has been followed by endogenous eczema. ${ }^{11,12}$ In our patients, xerosis (60\%) and atopic diathesis $(33.8 \%)$ have been most frequently observed, and $33.3 \%$ of the patients with xerosis have been associated with atopy. As far as we know, there is not any study examining the frequency of xerosis in patients with PN and the associated co-factors in the literature. In this study, only the presence of systemic co-factors among accompanying co-factors has been found to significantly increase the risk of xerosis-related PN (mainly the risk of non-atopic xerosis related $\mathrm{PN})$. Due to the fact that accompanying co-factors in PN patients with atopic xerosis did not reveal a significant risk for the presence of xerosis, we could consider that the main cause of xerosis and PN in these patients is atopy. Nevertheless, it should not be ignored that the small number of PN patients with atopic xerosis may also have contributed to these results.

In previous clinical studies, it has been observed that the lesions show a generalized distribution, which is similar to ours, in the majority of patients with PN whose average ages range between 45-62 years and whose disease durations range between 77.5-85.2 months. As in our patients, it has been observed that the lower extremities and the body are most frequently affected, and no significant relationship has been found between the number of the affected body areas and any PN-associated disease (Figure 1). ${ }^{10-12}$ Iking et al. have not found any correlation between age distribution or PN duration and the underlying disease, but they have reported that most of the associated systemic diseases have been observed in elderly patients and all of the patients in this group consisted of patients who are $>50$ years old. ${ }^{12}$ Besides, it has been stated by some authors that $\mathrm{PN}$ observed in atopic individuals has an earlier onset., ${ }^{911,12}$ In our patients, it has also been determined that PN has started at an advanced age (evident in the later adulthood) in the patient group with xerosis, that has been found to show more fre- 


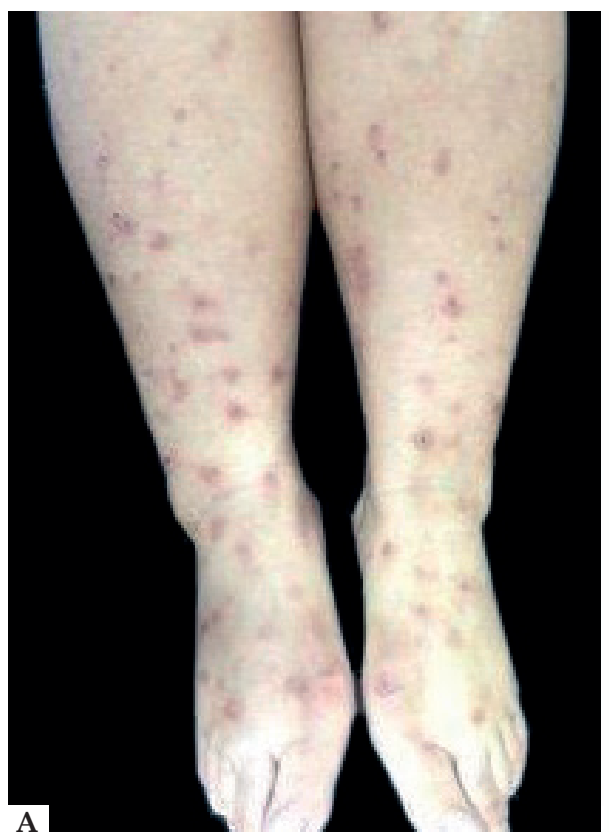

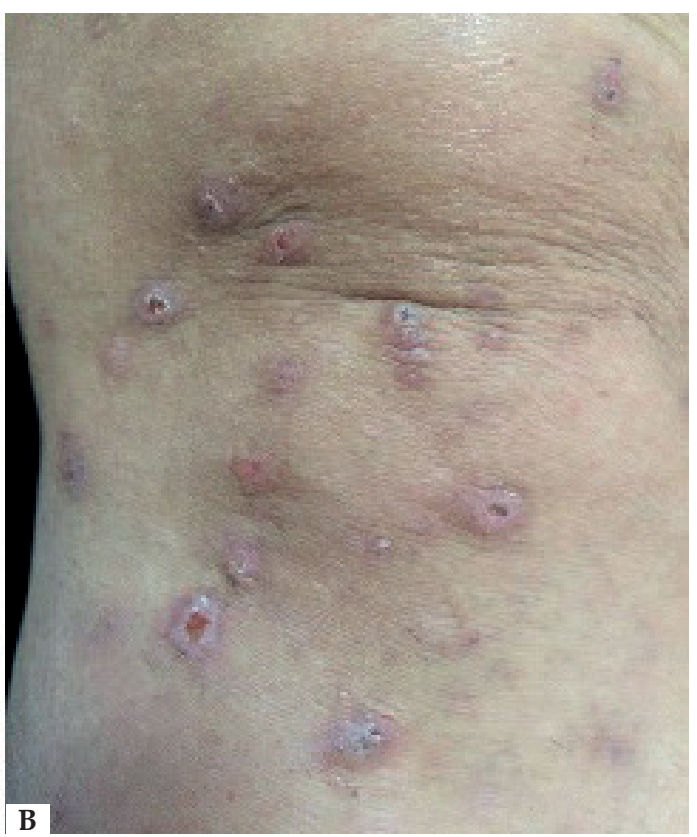

Figure 1: Excoriated papulonodular lesions on the extensor surfaces of the lower extremities quent association with mixed cofactors. Furthermore, in accordance with the literature, it has been observed that PN patients with atopic xerosis have an earlier onset compared to the non-atopic xerosis group and that the average PN duration has been probably longer in relation to this. The PN duration of the group with xerosis has been found to be shorter compared to those without xerosis although it has not been significant. The facts that the number of PN-associated co-factors in patients with xerosis is greater and that they have probably increased the triggering effects of each other may have contributed to the formation of lesions in a relatively shorter period of time.

In our study, the ratio of atopic diathesis in PN patients with xerosis was similar to the non-xerosis group; however, the presence of diabetes mellitus in the systemic cofactors was found to be significantly more compared to PN patients without xerosis. Sweat glands atrophy associated with autonomic neuropathy, microangiopathy, abnormal persistent cohesion between corneocytes, the increased transit time of corneocytes in stratum corneum and the altered skin barrier functions in diabetes mellitus play a role in the formation of xerosis. It has been suggested that hyperglycaemia and/or the decreased insulin signal may lead to a decrease in stratum corneum hydration in these cases. ${ }^{20}$ Furthermore, the fact that those with systemic cofactors accompanying PN, which is more significant in diabetes mellitus patients with xerosis in our study, are mostly found in the non-atopic xerosis group supports the idea that PN disease has a multifactorial origin rather than being a symptom of a single disease.

PN may lead to an impairment in the quality of life by causing sleep disorder, emotional load and even psychiatric disorders. On the other hand, it has also been mentioned in a limited number of case reports and small case series that psychosomatic factors can play a triggering role for $\mathrm{PN} .{ }^{11,21-23}$ Tan et al. have reported the presence of psychological cofactors such as habitual picking, anxiety, stress, impulse control disorder, depression and delusions of parasitosis in $30 \%$ of patients with PN. ${ }^{11}$ In the previous studies, it has been mostly focused on the fact that anxiety and depression ratios are higher in patients with PN. ${ }^{8,22,23}$ Furthermore, it has also been stated that psychosocial disorders can be observed synchronously in some patients with PN as in our study and that it may be difficult to determine whether these conditions in such cases are the cause or the result of PN. ${ }^{11,22}$ In this study, the presence of a psychological co-factor (most commonly depression) was seen in nearly half of PN patients with and without xerosis (atopic or non-atopic). In the literature, it has been shown that stress and depression may be associated with inflammation and may also play a role in $\mathrm{CP}$ formation by negatively affecting the skin barrier function or the psychoneuroendocrinological system. ${ }^{4,24}$ It has been reported that psychological stress leads to a decrease in the epidermal lipid synthesis and an increase in the transepidermal water loss associated with the increased production of endogenous glucocorticoids and thus causes the abnormalities in epidermal permeability barrier homeostasis and stratum corneum integrity. ${ }^{24}$ In our study, although the psychological co-factors in PN patients with xerosis have not differed compared to those without xerosis, the fact that the presence of anxiety is observed at higher rates in the non-atopic xerosis group compared to patients with atopic xerosis may suggest that psychological stress can lead to xerosis.

Recently, it has been emphasized that central or peripheral nervous system disorders (e.g. multiple sclerosis, brain tumors or abscesses, cerebral or spinal infarcts, brachioradial pruritus, notalgia paresthetica, post-herpetic neuralgia, small fibre neuropathy) 
can lead to neuropathic itching. ${ }^{25}$ It has been shown that neuropathic itching is accompanied by other sensory symptoms such as paresthesia, hyperesthesia and hypoesthesia in these diseases, and these symptoms have often been reported by patients with PN. ${ }^{12,25}$ The data demonstrating the relationship between PN and neurological disorders in the literature are quite insufficient. Neurological factors such as chronic pain syndrome, neuropathy, PUVA-pain, brachioradial pruritus and restless legs syndrome have been determined in $9.3 \%$ of the patients with PN by Iking et al. ${ }^{12}$ In our study, a neurological disease has been determined by $17.5 \%$ in patients with multifactorial-originated PN. It has been suggested that epidermal keratinocytes and Tlymphocytes infiltrating the skin as a result of itching in PN are the nerve growth factor source, and this may also lead to neurohyperplasia, sprouting in nerve fibers, and especially the up-regulation of neuropeptides such as substance-P. In PN skin biopsies, hyperplasia in the dermal substance-P-positive nerve fibers and a decrease in the density of intraepidermal nerve fibers have been observed. It has been thought that there is subclinical small-fibers sensorial neuropathy before the PN formation, and this can also be the main triggering factor because the decreased density in epidermal nerve fibers has been also determined in the normal-appearing skin of patients with PN. ${ }^{26,27}$ In the literature, the main cause of small fibre neuropathy has been defined as diabetes mellitus and it has been also found to be associated with diseases such as hypothyroidism, Sjögren disease, sarcoidosis, lupus erythematosus and gammopathy. The intraepidermal nerve fiber density analysis should be performed in the biopsy specimen taken from the lesional area or lateral lower leg for the diagnosis of neuropathic pruritus and small fibre neuropathy. ${ }^{25}$ However, since routine biopsies have not been taken and evaluated in this respect in our patients, it is not possible to talk about the presence of the small fibre neuropathy that may accompany PN lesions or associated diseases. On the other hand, it has been shown that nerve fibers and nerve growth factor levels increase in the epidermis of patients with xerosis. It has been thought that skin-scratching induces neuropeptide production in cutaneous nerve fibers and that the sensitivity of nerve fibers to mechanical stimuli can increase with the deterioration in the cutaneous barrier. Thus, it has been suggested that both xerosis and skin itching are the main factors leading to neurogenic inflammation. ${ }^{28}$ In our study, although the ratio of neurological diseases in PN patients with xerosis has been higher compared to non-xerosis ones, this difference has not been statistically significant.

This is the first study that has determined the frequency of xerosis in PN and evaluated its relationship both with demographic and clinical characteristics and accompanying $\mathrm{PN}$-associated factors. Furthermore, this is the first investigation on the large representative sample of the Turkish female PN patients. However, some limitations of this study such as the absence of the age-matched control group, the inclusion of only female patients, the absence of follow-up data, the fact that the diagnosis of xerosis has not been based on objective methods have to be also considered.

\section{CONCLUSION}

In conclusion, as a result of the present study, xerosis has been identified in more than half of the patients with PN and it has been determined that in most of the patients, xerosis is associated especially with diabetes mellitus and other conditions related to PN. Therefore, it has been considered that the presence of xerosis in patients with PN may contribute to both the triggering characteristic of the comorbid disease related to PN and itch-scratch vicious cycle. Further large prospective case-control studies with follow-up periods will be required to clearly assess the impact of xerosis and other associated co-factors on the clinical outcomes of PN. 


\section{REFERENCES}

1. Brenner S, Politi Y. Dermatologic diseases and problems of women throughout the life cycle. Int J Dermatol. 1995;34:369-79.

2. Flessner CA, Woods DW. Phenomenological characteristics, social problems, and the economic impact associated with chronic skin picking. Behav Modif. 2006;30: 944-63.

3. Ständer S, Stumpf A, Osada N, Wilp S, Chatzigeorgakidis E, Pfleiderer B. Gender differences in chronic pruritus: women present different morbidity, more scratch lesions and higher burden. Br J Dermatol. 2013;168:1273-80.

4. Stumpf A, Ständer S, Warlich B, Fritz F, Bruland P, Pfleiderer B et al. Relations between the characteristics and psychological comorbidities of chronic pruritus differ between men and women: women are more anxious than men. $\mathrm{Br} J$ Dermatol. 2015;172:1323-8.

5. Tsianakas A, Zeidler C, Ständer S. Prurigo nodularis management. Curr Probl Dermatol. 2016;50:94-101.

6. Zeidler C, Ständer S. The pathogenesis of prurigo nodularis - 'Super-Itch' in exploration. Eur J Pain. 2016;20:37-40.

7. Fostini AC, Girolomoni G, Tessari G. Prurigo nodularis: an update on etiopathogenesis and therapy. J Dermatolog Treat. 2013;24:458-62.

8. Rowland Payne CM, Wilkinson JD, McKee PH, Jurecka W, Black MM. Nodular prurigo--a clinicopathological study of 46 patients. Br J Dermatol. 1985;113:431-9.

9. Tanaka M, Aiba S, Matsumura N, Aoyama H, Tagami H. Prurigo nodularis consists of two distinct forms: early-onset atopic and late-onset non-atopic. Dermatology. 1995;190:269-76.

10. Winhoven SM, Gawkrodger DJ. Nodular prurigo: metabolic diseases are a common association. Clin Exp Dermatol. 2007;32:224-5.

11. Tan WS, Tey HL. Extensive prurigo nodularis: characterization and etiology. Dermatology. 2014;228:276-80.

12. Iking A, Grundmann S, Chatzigeorgakidis E, Phan NQ, Klein D, Ständer S. Prurigo as a symptom of atopic and non-atopic diseases: aetiological survey in a consecutive cohort of 108 patients. J Eur Acad Dermatol Venereol. 2013;27:550-7.

13. Matterne U, Apfelbacher CJ, Vogelgsang L, Loerbroks A, Weisshaar E. Incidence and determinants of chronic pruritus: a population-based cohort study. Acta Derm Venereol. 2013;93:532-7.

14. Al-Nuaimi Y, Sherratt MJ, Griffiths CE. Skin health in older age. Maturitas. 2014;79:256-64.

15. Biniek K, Kaczvinsky J, Matts P, Dauskardt RH. Understanding age-induced alterations to the biomechanical barrier function of human stratum corneum. $J$ Dermatol Sci. 2015;80:94-101.
16. Ständer S, Weisshaar E, Mettang T, Szepietowski JC, Carstens E, Ikoma A, et al. Clinical classification of itch: a position paper of the International Forum for the Study of Itch. Acta Derm Venereol. 2007;87:291-4.

17. Hay RJ, Johns NE, Williams HC, Bolliger IW, Dellavalle RP, Margolis DJ, et al. The global burden of skin disease in 2010: An analysis of the prevalence and impact of skin conditions. J Invest Dermatol. 2014;134:1527-34.

18. Paul C, Maumus-Robert S, Mazereeuw-Hautier J, Guyen CN, Saudez X, Schmitt AM. Prevalence and risk factors for xerosis in the elderly: a cross-sectional epidemiological study in primary care. Dermatology. 2011;223:260-5.

19. Polat M, Oztas P, Ilhan MN, Yalçin B, Alli N. Generalized pruritus: a prospective study concerning etiology. Am J Clin Dermatol. 2008:9:39-44.

20. Sakai S, Kikuchi K, Satoh J, Tagami H, Inoue S. Functional properties of the stratum corneum in patients with diabetes mellitus: similarities to senile xerosis. Br J Dermatol. 2005;153:319-23.

21. Schneider G, Hockmann J, Ständer S, Luger TA, Heuft G. Psychological factors in prurigo nodularis in comparison with psoriasis vulgaris: results of a case-control study. Br J Dermatol. 2006;154:61-6.

22. Dazzi C, Erma D, Piccinno R, Veraldi S, Caccialanza M. Psychological factors involved in prurigo nodularis: A pilot study. J Dermatolog Treat. 2011;22:211-4.

23. Jørgensen KM, Egeberg A, Gislason GH, Skov L, Thyssen JP. Anxiety, depression and suicide in patients with prurigo nodularis. J Eur Acad Dermatol Venereol. 2017;31:e106-7.

24. Fukuda S, Baba S, Akasaka T. Psychological stress has the potential to cause a decline in the epidermal permeability barrier function of the horny layer. Int $J$ Cosmet Sci. 2015;37:63-9

25. Brenaut E, Marcorelles P, Genestet S, Ménard D, Misery L. Pruritus: an underrecognized symptom of small-fiber neuropathies. J Am Acad Dermatol. 2015;72:328-32.

26. Schuhknecht B, Marziniak M, Wissel A, Phan NQ, Pappai D, Dangelmaier J, et al. Reduced intraepidermal nerve fibre density in lesional and nonlesional prurigo nodularis skin as a potential sign of subclinical cutaneous neuropathy. $\mathrm{Br}$ Dermatol. 2011;165:85-91.

27. Bobko S, Zeidler C, Osada N, Riepe C, Pfleiderer B, Pogatzki-Zahn E, et al. Intraepidermal nerve fibre density is decreased in lesional and inter-lesional prurigo nodularis and reconstitutes on healing of lesions. Acta Derm Venereol. 2016:96:404-6.

28. Tominaga M, Ozawa S, Tengara S, Ogawa H, Takamori K. Intraepidermal nerve fibers increase in dry skin of acetone-treated mice. J Dermatol Sci. 2007;48:103-11.

\section{AUTHORS'CONTRIBUTIONS}

Sevgi Akarsu

(iD) ORCID 0000-0001-8418-2953

Statistical analysis, Approval of the final version of the manuscript, Design and planning of the study, Preparation and writing of the manuscript, Effective participation in research orientation, Critical review of the literature, Critical review of the manuscript Ozlem Ozbagcivan iD ORCID 0000-0001-7190-3969

Approval of the final version of the manuscript, Design and planning of the study, Preparation and writing of the manuscript, Effective participation in research orientation, Critical review of the literature, Critical review of the manuscript

Turna Ilknur (iD) ORCID 0000-0003-2136-6098

Approval of the final version of the manuscript, Intellectual participation in propaedeutic and/or therapeutic conduct of studied cases, Critical review of the manuscript
Fatma Semiz iD ORCID 0000-0003-1066-6773

Approval of the final version of the manuscript, Collecting, analysis and interpretation of data, Effective participation in research orientation, Critical review of the manuscript $\begin{array}{lll}\text { Burcu Bahar Inci } & \text { (iD) ORCID 0000-0002-6414-9643 }\end{array}$ Approval of the final version of the manuscript, Collecting, analysis and interpretation of data, Effective participation in research orientation, Critical review of the manuscript Emel Fetil (iD) ORCID 0000-0003-2927-9052

Approval of the final version of the manuscript, Intellectual participation in propaedeutic and/or therapeutic conduct of studied cases, Critical review of the manuscript

How to cite this article: Akarsu S, Ozbagcivan O, Ilknur T, Semiz F, Inci BB, Fetil E. Xerosis cutis and associated co-factors in women with prurigo nodularis. An Bras Dermatol. 2018;93(5):671-9. 